\title{
Adipokines in the skeleton: influence on cartilage function and joint degenerative diseases
}

\author{
Rodolfo Gomez, Francisca Lago', Juan Gomez-Reino, Carlos Dieguez ${ }^{2}$ and Oreste Gualillo \\ Research Laboratory 9 (NEIRID LAB, Laboratory of Neuro Endocrine Interactions in Rheumatology and Inflammatory Diseases), Santiago University Clinical Hospital, Calle Choupana \\ $\mathrm{s} / \mathrm{n}$, Edificio C, Planta -2, 15706 Santiago de Compostela, Spain \\ ${ }^{1}$ Research Laboratory 7 (Molecular and Cellular Cardiology), Santiago University Clinical Hospital, Santiago de Compostela, Spain \\ ${ }^{2}$ Department of Physiology, School of Medicine, Santiago University, Santiago de Compostela, Spain \\ (Correspondence should be addressed to O Gualillo; Email: oreste.gualillo@usc.es)
}

\begin{abstract}
The discovery of leptin in 1994 marked the beginning of a new understanding about white adipose tissue (WAT) and modified a static vision of this tissue which was viewed up to the end of the 20th century as an inert tissue, devoted to body protection from heat loss and to passively storing energy. The identification of the product of the gene obese accentuated the role of adipose tissue in the physiopathology of obesity-linked diseases, and led to the discovery of various adipokines, many of a pro-inflammatory nature. It has become progressively manifest that WAT-derived adipokines can now be considered as the fulcrum between obesity-related environmental causes, such as nutrition and lifestyle, and the biochemical shifts that lead to metabolic syndrome, inflammatory and/or autoimmune conditions, and rheumatic diseases. Herein, we review recent adipokine research, with particular emphasis to the role of leptin, adiponectin, resistin, and visfatin in chondrocyte function and skeleton, as well as in inflammatory and degenerative cartilage joint diseases.
\end{abstract}

Journal of Molecular Endocrinology (2009) 43, 11-18

\section{Introduction}

By contrast to earlier beliefs, white adipose tissue (WAT) is not merely a fat store but it is a dynamic player controlling body homeostasis and its active role was tangible with the discovery of leptin in Zhang et al. (1994). This $16 \mathrm{kDa}$ protein is the product of the gene obese $(o b)$, which is mutated in a murine form of hereditary obesity. Since then, WAT has been found to generate more than 50 cytokines and other molecules (Rasouli \& Kern 2008). These 'adipokines' exert their action through endocrine, paracrine, autocrine or juxtacrine cross-talk in a wide variety of physiological or physiopathological processes, including immunity and inflammation (Otero et al. 2005a). It is noteworthy that several adipokines are also produced by WAT infiltrating macrophages or by WAT stromal cells which maintain an active cross-talk with adipocytes by increasing and/or perpetuating immune dysfunction and systemic/local inflammation (Heilbronn \& Campbell 2008).

Obesity, the circumstance initially spurring the flood of research on WAT, is at present commonly considered as a pro-inflammatory state, characterized by the increase of several markers of inflammation and acute-phase reactants. Adipokines consist of a miscellany of pro-inflammatory (and in some cases also antiinflammatory) peptides including tumor necrosis factor $(\mathrm{TNF} \alpha)$, production of which by fat cells was observed even before the discovery of leptin; Hotamisligil et al. (1993). Pro-inflammatory adipokines appear to contribute strikingly to the so-called 'low-grade inflammatory state' of obese subjects, setting up a cluster of metabolic aberrations including insulin resistance, dyslipidaemia, and alteration of coagulation that is associated with an increased risk of cancer, type II diabetes, cardiovascular complications and with an increased propensity to develop autoimmune inflammatory diseases (Fantuzzi 2008).

WAT also produces, likely as an adaptive response, anti-inflammatory factors such as interleukin 1 (IL 1) receptor antagonist and IL 10 (Juge-Aubry \& Meier 2002, Trayhurn 2005). Indeed, IL $1 \mathrm{Ra}$ is an antiinflammatory cytokine that is markedly increased in human obesity; data from rodents strongly suggest that this peptide has important central and peripheral metabolic functions (Juge-Aubry et al. 2005).

DOI: 10.1677/JME-08-0131 Online version via http://www.endocrinology-journals.org 


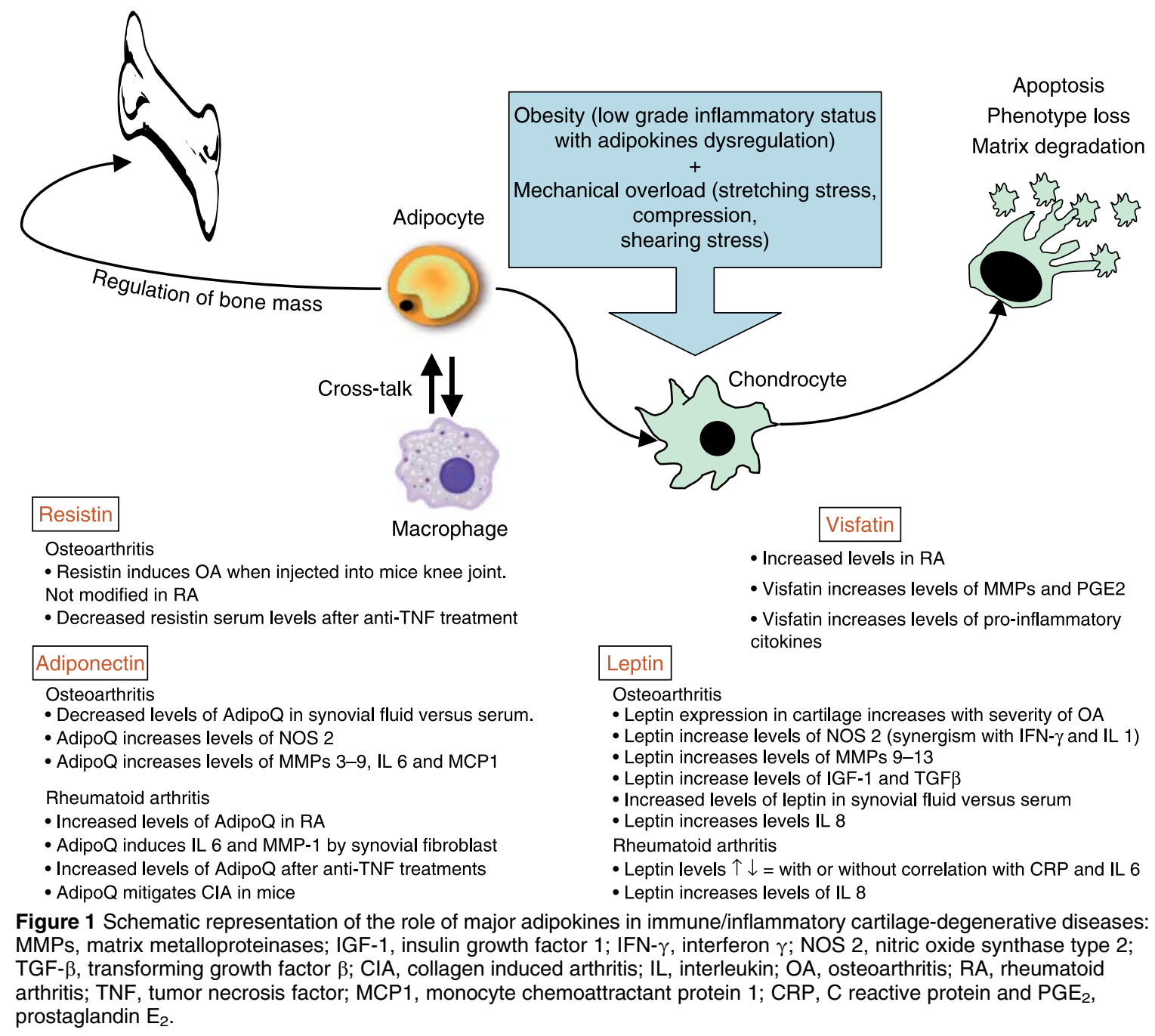

This review will address present knowledge about the involvement of the most relevant adipokines in the physiology of skeleton with a particular focus on chondrocyte function (Fig. 1).

\section{Leptin: the harbinger}

Leptin is a $16 \mathrm{kDa}$ non-glycosylated hormone encoded by the gene $o b$, the murine homologue of the human gene LEP (Zhang et al. 1994). It belongs to the class I cytokine superfamily, consisting of a bundle of four $\alpha$-helices. It is mostly produced by adipocytes, and circulating leptin levels are correlated with WAT mass. It decreases food intake and increases energy consumption by acting on hypothalamic nuclei, inducing anorexigenic factors cocaine amphetamine related transcript (CART), pro-opiomelanocortin and suppressing orexigenic neuropeptides such as neuropeptide $\mathrm{Y}$, agouti related protein, and orexin (Ahima et al. 1996). Leptin levels are mainly dependent on the amount of body fat, but its synthesis is also regulated by sex hormones and a wide range of inflammation mediators (Sarraf et al. 1997, Gualillo et al. 2000). As a result of the effects of sex hormones, leptin levels are higher in women than in men even when adjusted for body mass index, which may be relevant to the influence of sex on the development or frequency of certain diseases, such as osteoarthritis (Blum et al. 1997, Teichtahl et al. 2005).

It can easily be defined as a cytokine-like hormone with pleiotropic actions. Leptin operates on target cells by binding to its OB-Rb long form receptor isoform which is encoded by the gene diabetes $(d b)$ and belongs to the class 1 cytokine receptor superfamily. Indeed, alternative splicings of the $d b$ gene produce multiple isoforms which are not functional. As in the case of other class I cytokine receptors, the main routes by which $\mathrm{Ob}-\mathrm{Rb}$ appears to transmit the extracellular 
signal it receives are janus kinase (JAK)-signal transducers and activators of transcription (STAT) pathways (Fruhbeck 2006), which involve JAK2 phosphorylating tyrosines in the cytoplasmic domain of the receptor. In particular, mutation of the intracellular tyrosine Y1138 of murine $\mathrm{Ob}-\mathrm{Rb}$ prevents STAT3 activation and results in hyperphagia, obesity and impaired thermoregulation, and replacing Y1138 with a serine residue likewise causes pronounced obesity in knock-in mice. However, since Y1138S knock-in mice do not exhibit other defects of $d b / d b$ mice, such as infertility, the role of leptin in the processes that are disrupted in these latter conditions must be independent of STAT3 (Bates et al. 2003). Indeed, the other two cytoplasmic tyrosines of murine Ob-Rb, Y985, and Y1077, have been shown to bind other intracellular signaling molecules (Gualillo et al. 2002, Fruhbeck 2006).

\section{Leptin: a mediator of immuno-inflammatory response}

$A b / d b$ leptin receptor deficient mice are affected by thymus atrophy, and $o b / o b$ leptin deficient mice are immunodeficient (Kimura et al. 1998). This in all probability, explains why the immune system in murine models is depressed by malnourishment and food restriction both of which result in low leptin levels, and why this depression is reverted by administration of exogenous leptin (Howard et al. 1999). Known direct actions of leptin on immune responses have been recently reviewed and include modulation of monocytes/macrophages, neutrophils, basophils, eosinophils, natural killer, and dendritic cells (Matarese et al. 2007). But a focal point of the most part of the studies on the interaction between leptin and immune system was the demonstration that it modifies T-cell balance, induces T-cell activation, and changes the pattern of T-cell cytokine production by driving T-cell differentiation towards a T-cell helper $1\left(\mathrm{~T}_{\mathrm{H} 1}\right)$ response, accounting for a pro-inflammatory role of leptin in several models of autoimmune/inflammatory conditions (Sanna et al. 2003).

A remarkable aspect of the effects of leptin in the immune system is its action as a pro-inflammatory cytokine: it is produced by inflammatory cells, and leptin mRNA expression and circulating leptin levels are increased by a number of inflammatory stimuli, including IL 1, IL 6, and lipopolysaccharide (LPS; Faggioni et al. 2001).

Another relevant aspect of the biological activity of leptin on immune system has been recently revealed by the group of Matarese et al. Indeed, these authors demonstrated that leptin neutralization directly reversed anergy and T-cell receptor hyporesponsiveness of regulatory $\mathrm{T}$ cells, providing new insights about the role of leptin in autoimmunity (Matarese et al. 2007). Leptin is a relevant regulator of bone remodeling, a homeostatic function maintaining bone mass constant. Indeed, after binding to its receptors on hyphothalamic neurons, leptin regulates, by targeting only one cell type, the osteoblast, bone formation (via the sympathetic nervous system (SNS)), and osteoclast differentiation (via SNS and CART; Takeda \& Karsenty 2008).

Together with a host of other immune and neuroendocrine signals, leptin seems to play a role in autoimmune diseases such as rheumatoid arthritis (RA), but whether it can hurt or save from harm joints structures in RA is still unclear. In patients with RA, circulating leptin levels have been described as higher or unmodified in comparison with healthy controls (Bokarewa et al. 2003, Otero et al. 2006). In RA patients, a food restriction-induced decrease in circulating leptin is associated with $\mathrm{CD} 4+$ lymphocyte hyporeactivity and increased IL 4 secretion (Fraser et al. 1999). Experimental antigen-induced arthritis is less severe in $o b / o b$ mice than in WT littermate, whereas $o b / o b$ and $d b / d b$ mice exhibited a delayed resolution of inflammatory process in zymosan-induced experimental arthritis. To note, leptin decreased the severity of septic arthritis in wildtype mice. So, in the light of the present results, it is almost difficult to make an unmistakable conclusion about the role of leptin in RA (Bernotiene et al. 2006). It is noteworthy that leptin induces IL 8 via leptin receptor, insulin receptor substrate 1, phosphatidylinositol-3-kinase (PI3K), protein kinase $\mathrm{B}$ cascade, and promotion of nuclear factor $\mathrm{K} \beta(\mathrm{NF}-\mathrm{k} \beta) / \mathrm{p} 300$ binding in human synovial fibroblast from RA patients as well as from OA subjects (Tong et al. 2008).

In osteoarthritis, leptin expression is much higher in osteoarthritic human cartilage than in normal cartilage. The initial finding that administration of exogenous leptin increases insulin growth factor-1 (IGF1) and transforming growth factor $\beta-1$ production by rat knee joint cartilage has suggested that high circulating leptin levels in obese individuals may protect cartilage from osteoarthritic degeneration (Dumond et al. 2003). However, under pathological conditions, control of matrix homeostasis by chondrocytes in the joint is lost, and most of the evidence points the other way. In cultured human and murine chondrocytes, type 2 nitric oxide synthase (NOS2) is synergistically activated by the combination of leptin plus interferon- $\gamma$, and NOS2 activation by IL 1 is increased by leptin via a mechanism involving JAK2, PI3K, and mitogen activated kinases (MEK1 and p38; Otero et al. 2003, 2005b). Recently, it has been demonstrated that leptin is able to induce also the synthesis of relevant matrix metalloproteases (MMPs) involved in cartilage damage, such as MMP9 and MMP13. To note, small interference RNA against leptin deactivated directly MMP-13, which was up-regulated after leptin's epigenetic reactivation (Iliopoulos et al. 2007, Simopoulou et al. 2007). All these data 
suggest that osteoarthritis is a metabolic disease induced by local abnormal leptin activity (Lajeunesse et al. 2005). A proinflammatory effect of leptin on cartilage would be in keeping with the fact that, in comparison with men, women have both higher circulating leptin levels and a greater propensity to develop osteoarthritis (Gualillo 2007). It might explain the relationship between obesity and inflammatory conditions, especially those related with alterations of cartilage homeostasis. Finally, leptin affects growth plate cartilage development through a extracellular signal regulated kinase-1/2 and STAT5 chondrocyte differentiation-dependent pathway, whereas p38 kinase is not essential for leptin- induced collagen type X-expression (Ben-Eliezer et al. 2007).

\section{Adiponectin}

Adiponectin, (GBP28, apM1, Acrp30, AdipoQ), is a 244residue protein that is produced largely by WAT. It increases fatty acid oxidation and reduces the synthesis of glucose in the liver. Ablation of the adiponectin gene has no dramatic effect on knock-out mice on a normal diet, but when placed on a high-fat/sucrose diet they develop severe insulin resistance and exhibit lipid accumulation in muscles (Whitehead et al. 2006). Circulating adiponectin levels tend to be low in morbidly obese patients and increase with weight loss and with the use of thiazolidinediones, which enhance sensitivity to insulin (Maeda et al. 2001, Kadowaki \& Yamauchi 2005).

Adiponectin acts via two receptors, one (AdipoR1) found predominantly in skeletal muscle and the other (AdipoR2) in liver (Kadowaki \& Yamauchi 2005). Transduction of the adiponectin signal by AdipoR1 and AdipoR2 involves the activation of AMP-activated protein kinase peroxisome proliferator activated receptors (PPARs; $\alpha$ and $\gamma$ ) and seemingly other signal molecules. To note, targeted disruption of AdipoR1 and AdipoR2 causes abrogation of adiponectin binding and all its metabolic actions (Yamauchi et al. 2007). Adiponectin presents structural homology with collagen VIII and X and complement factor Clq, and circulates in the blood in relatively large amounts in oligomeric forms (trimers and hexamers, but also a 12-18-mer form, constituting about $0.01 \%$ of total plasma protein. The grade of oligomerization state might be responsible for the differential activity of the protein but this is at present somewhat controversial and may depend on target cell type.

Adiponectin was discovered almost at the same time as leptin; however, its role in defending against obesity-complications was recognized only some years later. At present, some evidence indicates that it has a wide range of effects in pathologies with inflammatory components, such as endothelial dysfunction, cardiovascular disease, type 2 diabetes, metabolic syndrome, and RA (Matsuzawa 2006). Adiponectin acts as a potent modulator of both $\mathrm{B}$ and $\mathrm{T}$ cells; in addition, it modulates the activity of immune innate response (monocyte-macrophage, and dendritic cells) by inducing relevant anti-inflammatory factors such as IL 1 receptor antagonist and IL 10 (Kadowaki \& Yamauchi 2005).

In contrast to its previously envisaged 'protective' role against obesity and vascular diseases, there is some evidence that adiponectin in skeletal joints might act as a pro-inflammatory agent and might be involved in matrix degradation. Adiponectin levels in RA patients are higher than in healthy subjects and adiponectin levels in synovial fluid are higher in RA patients than in patients with osteoarthritis (Schaffler et al. 2003, Otero et al. 2006). In human synovial fibroblasts adiponectin selectively induces, via the p38 MAPK pathway, two of the main mediators of RA, IL 6, and matrix metalloproteinase 1 (Ehling et al. 2006). Chondrocytes also present functional adiponectin receptors, activation of which leads to the induction of type 2 NOS via a signaling pathway that involves PI3 kinase; and adiponectin-treated chondrocytes similarly increase IL 6, MMP3, MMP9, and MCP1 synthesis (but not release of prostaglandin $\mathrm{E}_{2}$ or leukotriene $\mathrm{B}_{4}$ or TNF; Lago et al. 2008). Taken together, these results suggest that it may be worth considering adiponectin as a potential molecule involved in degenerative joint diseases. On the other hand, the high adiponectin levels of patients with RA can also be interpreted as an attempt to overcome the well-known pro-inflammatory effect of leptin, for example by counteracting the proinflammatory effects of TNF- $\alpha$ and reducing the production of IL 6 and $\mathrm{C}$ reactive protein in RA. In keeping with this data, recent reports showed that adiponectin mitigates the severity of collagen-induced arthritis in mice (Lee et al. 2008) whereas another work showed that Etanercept (a soluble fusion protein that specifically binds to TNF- $\alpha$ ) treatment in RA patients is able to increase adiponectin levels in women with RA (Lewicki et al. 2008). This finding has been also suggested by another author using another anti TNF- $\alpha$ treatment such as infliximab (Nagashima et al. 2008).

\section{Resistin}

Resistin is a dimeric protein that received its name from its apparent induction of insulin resistance in mice. It belongs to the found in inflammatory zones (FIZZ) family (also known as RELMs, resistin-like molecules). Resistin (FIZZ3) has been found in adipocytes, macrophages, and other cell types (Steppan et al. 2001). 
It has been postulated that resistin mediates insulin resistance, but this role may be limited to rodents. Earlier excitement for this theory, which provides a direct connection between adiposity and insulin resistance, was rapidly extinguished by contradictory findings in both mice and humans (Steppan et al. 2001).

That resistin is engaged in inflammatory conditions in humans is suggested by its secretion in substantial quantities by mononuclear cells. Also, resistin levels are mutually related with those of cell adhesion molecules such as intercellular adhesion molecule 1 (ICAM1) in patients with obstructive sleep apnea, and in atherosclerotic patients are positively associated with other markers of inflammation, such as soluble TNF-R type II and lipoprotein-associated phospholipase A2 (Harsch et al. 2004, Reilly et al. 2005). Furthermore, LPS has been reported to induce resistin gene expression in primary human and murine macrophages via a cascade involving the secretion of pro-inflammatory cytokines, and in human peripheral blood mononuclear cells resistin appears both to induce and be induced by IL6 and TNF- $\alpha$ (induction of these cytokines by resistin occurring via the NFКB pathway; Lehrke et al. 2004, Bokarewa et al. 2005).

There are demonstrations that resistin may also be involved in the pathogenesis of RA: resistin has been found in the plasma and the synovial fluid of RA patients, and injection of resistin into mice joints induces an arthritis-like condition, with leukocyte infiltration of synovial tissues, hypertrophy of the synovial layer, and pannus formation (Bokarewa et al. 2005, Senolt et al. 2007). However, plasma resistin levels in RA patients appear similar to those found in healthy controls and although in some studies of RA patients resistin levels were higher in synovial fluid than in serum (which shows that circulating levels of adipokines do not necessarily reflect the situation in the joint), the discrepancy may be due simply to the increased permeability of inflamed synovial membrane (Otero et al. 2006, Schaffler et al. 2003, Bokarewa et al. 2005). To note, a recent report indicated that RA patients treated with monoclonal anti TNF- $\alpha$ antibody infliximab is able to reduce serum resistin. At present, no other data are available to establish a defined role of resistin at joint level and specifically chondrocytes are likely to be no responsive to resistin in turns of metabolic activity, differentiation and/or nitric oxide production (unpublished personal data).

\section{Visfatin}

Visfatin is a peptide that was originally discovered in liver, skeletal muscle, and bone marrow as a growth factor for B-lymphocyte precursors (whence its alternative names, pre-B-colony enhancing factor, and nicotinamide phosphorybosil transferase, NAMPT) which is supposed to have insulin mimetic properties; however, the role of visfatin in the modulation of glucose metabolism, as well as its binding to insulin receptor is still debated (Jia et al. 2004, Fukuhara et al. 2005, 2007). It is up-modulated in models of acute lung injury and sepsis (Jia et al. 2004). Circulating visfatin levels are closely correlated with WAT accumulation, visfatin mRNA levels increase in the course of adipocyte differentiation, and visfatin synthesis is regulated by several factors, including glucocorticoids, TNF- $\alpha$, IL 6 , and GH. However, visfatin is not only produced by WAT, but also by endotoxin-challenged neutrophils, in which it prevents apoptosis through a mechanism mediated by caspases 3 and 8 (Jia et al. 2004). Also, patients with inflammatory bowel diseases have elevated circulating visfatin levels and increased levels of visfatin mRNA in their intestinal epithelium. Visfatin has been shown to induce chemotaxis and the production of IL $1 \beta$, $\mathrm{TNF} \alpha$, IL 6 , and costimulatory molecules by CD14+ monocytes, and to increase their ability to induce alloproliferative responses in lymphocytes, effects which are mediated intracellularly by p38 and MEK1 (Moschen et al. 2007). In addition, circulating visfatin is higher in patients with RA than in healthy controls (Otero et al. 2006). Even though it is presently unclear what the physiological role or relevance of visfatin is in the context of RA, it may reflect modulation of the inflammatory or immune response by visfatin, form part of a compensatory mechanism that promotes the accumulation of intra-abdominal fat so as to prevent rheumatoid cachexia, or it may simply be an epiphenomenon. Recently, the role of visfatin at joint cartilage and synovial level is going to be enlightened. Indeed, after the initial observation of increased visfatin circulating levels in RA patients by our group (Otero et al. 2006), other evidence pointed to a proinflammatory role of visfatin both in chondrocytes and synovial fibroblast (Brentano et al. 2007, Gosset et al. 2008) suggesting a role for visfatin as a destructive mediator of joint inflammation.

\section{Conclusions}

It is at present evident that adipokines play multiple relevant roles in the body, and the rising interest in this area is uncovering, step by step, the intricate adipokinemediated net among WAT, metabolic disorders, and inflammatory (auto)immune diseases. Although many aspects are still muddled, in this section, we briefly try to delineate some potential scenarios for therapeutics that this work has already opened.

Strong evidence suggests that high circulating leptin levels promote inflammation. So, it might be plausible to control bioavailable circulating leptin, and 
afterwards to forestall leptin-driven inflammation, by means of a soluble, high-affinity leptin-binding molecule in a similar strategy to the soluble TNF- $\alpha$ receptors used to treat RA. In addition, another way to contrast leptin activity might consist in thwarting the leptin receptor with monoclonal humanized antibodies or mutant leptin analogues that are able to bind to the receptor without activating it. Of course, central receptors mediating the influence of leptin on food intake should not be blocked, since the consequence should be hyperphagia and obesity. Indeed, the fact that this influence is exerted in the brain, on the other side of the blood-brain barrier, would seem to make such discrimination possible. At present, little is known in this area because present anti-leptin agents were developed to control the adipostatic effects of leptin, and hence to cross the blood-brain barrier.

Pharmacological strategies might work also for visfatin inhibition. A recent report by Busso et al. (2008) showed that pharmacological inhibition of visfatin with APO866 (also known as FK866 and WK-175) reduces severity of collagen-induced arthritis in mice (an experimental model of joint inflammation in with visfatin is elevated in serum and in arthritic paw) with comparable activity to etanercept. Moreover, NAMPT inhibition reduced NAD concentration and pro-inflammatory cytokine secretion in inflammatory cells.

The impact of potential biotherapies aimed to control systemic and/or local pro-inflammatory adipokines production deserves further and extensive research. Indeed, the present knowledge is almost incomplete to allow translation of these approaches to the clinical practice. Regardless of pharmacological perspectives, it is beyond doubt that the first determinant of the hyperproduction of pro-inflammatory adipokines in obesity is due to the abnormal deposition and functionality of intra-abdominal fat. So, the reduction of visceral adipose tissue, the control of overeating, and the increase of moderate physical activity remain the essential preventive strategies to counteract the detrimental side effects of obesity-driven pro-inflammatory state.

Only further insights into the intimate mechanisms regulating central and peripheral activity of adipokines might in the future propose attractive and functional pharmacological approaches.

\section{Declaration of interest}

There are no conflicts of interest.

\section{Funding}

Part of the research described in this review was supported by the Spanish Ministry of Health through the Fondo de Investigación Sanitaria, Instituto de Salud Carlos III (contracts PI05/0525,
PI050419, PI060919, PI08/0040, and PI08/0044). Rodolfo Gómez is a pre-doctoral fellow funded by Instituto de Salud Carlos III (FIS-PI05/0525). The work of Oreste Gualillo and Francisca Lago is funded by the Instituto de Salud Carlos III and the Xunta de Galicia (SERGAS) through a research staff stabilization contract.

\section{Acknowledgements}

The technical help of Veronica Lopez and Beatriz Malvar is kindly acknowledged. We apologize to the authors of the many relevant papers, mention of which in this review has been prevented due to shortage of space.

\section{References}

Ahima RS, Prabakaran D, Mantzoros C, Qu D, Lowell B, Maratos-Flier E \& Flier JS 1996 Role of leptin in the neuroendocrine response to fasting. Nature 382 250-252.

Bates SH, Stearns WH, Dundon TA, Schubert M, Tso AW, Wang Y, Banks AS, Lavery HJ, Haq AK, Maratos-Flier E et al. 2003 STAT3 signalling is required for leptin regulation of energy balance but not reproduction. Nature 421 856-859.

Ben-Eliezer M, Phillip M \& Gat-Yablonski G 2007 Leptin regulates chondrogenic differentiation in ATDC5 cell-line through JAK/ STAT and MAPK pathways. Endocrine 32 235-244.

Bernotiene E, Palmer G \& Gabay C 2006 The role of leptin in innate and adaptive immune responses. Arthritis Research and Therapy 8217.

Blum WF, Englaro P, Hanitsch S, Juul A, Hertel NT, Muller J, Skakkebaek NE, Heiman ML, Birkett M, Attanasio AM et al. 1997 Plasma leptin levels in healthy children and adolescents: dependence on body mass index, body fat mass, gender, pubertal stage, and testosterone. Journal of Clinical Endocrinology and Metabolism 82 2904-2910.

Bokarewa M, Bokarew D, Hultgren O \& Tarkowski A 2003 Leptin consumption in the inflamed joints of patients with rheumatoid arthritis. Annals of the Rheumatic Diseases 62 952-956.

Bokarewa M, Nagaev I, Dahlberg L, Smith U \& Tarkowski A 2005 Resistin an adipokine with potent proinflammatory properties. Journal of Immunology 174 5789-5795.

Brentano F, Schorr O, Ospelt C, Stanczyk J, Gay RE, Gay S \& Kyburz D 2007 Pre-B cell colony-enhancing factor/visfatin, a new marker of inflammation in rheumatoid arthritis with proinflammatory and matrix-degrading activities. Arthritis and Rheumatism 56 2829-2839.

Busso N, Karababa M, Nobile M, Rolaz A, Van Gool F, Galli M, Leo O, So A \& De Smedt T 2008 Pharmacological inhibition of nicotinamide phosphoribosyltransferase/visfatin enzymatic activity identifies a new inflammatory pathway linked to NAD. PLoS ONE 3 e2267.

Dumond H, Presle N, Terlain B, Mainard D, Loeuille D, Netter P \& Pottie P 2003 Evidence for a key role of leptin in osteoarthritis. Arthritis and Rheumatism 48 3118-3129.

Ehling A, Schaffler A, Herfarth H, Tarner IH, Anders S, Distler O, Paul G, Distler J, Gay S, Scholmerich J et al. 2006 The potential of adiponectin in driving arthritis. Journal of Immunology 176 4468-4478.

Faggioni R, Feingold KR \& Grunfeld C 2001 Leptin regulation of the immune response and the immunodeficiency of malnutrition. FASEB Journal 15 2565-2571.

Fantuzzi G 2008 Adiponectin and inflammation: consensus and controversy. Journal of Allergy and Clinical Immunology 121 326-330.

Fraser DA, Thoen J, Reseland JE, Forre O \& Kjeldsen-Kragh J 1999 Decreased CD4+ lymphocyte activation and increased interleukin4 production in peripheral blood of rheumatoid arthritis patients after acute starvation. Clinical Rheumatology 18 394-401. 
Fruhbeck G 2006 Intracellular signalling pathways activated by leptin. Biochemistry Journal 393 7-20.

Fukuhara A, Matsuda M, Nishizawa M, Segawa K, Tanaka M, Kishimoto K, Matsuki Y, Murakami M, Ichisaka T, Murakami H et al. 2005 Visfatin: a protein secreted by visceral fat that mimics the effects of insulin. Science 307 426-430.

Fukuhara A, Matsuda M, Nishizawa M, Segawa K, Tanaka M, Kishimoto K, Matsuki Y, Murakami M, Ichisaka T, Murakami H et al. 2007 Retraction. Science 318565.

Gosset M, Berenbaum F, Salvat C, Sautet A, Pigenet A, Tahiri K \& Jacques C 2008 Crucial role of visfatin/pre-B cell colony-enhancing factor in matrix degradation and prostaglandin $\mathrm{E}_{2}$ synthesis in chondrocytes: possible influence on osteoarthritis. Arthritis and Rheumatism 58 1399-1409.

Gualillo O 2007 Further evidence for leptin involvement in cartilage homeostases. Osteoarthritis and Cartilage 15 857-860.

Gualillo O, Eiras S, Lago F, Dieguez C \& Casanueva FF 2000 Elevated serum leptin concentrations induced by experimental acute inflammation. Life Sciences 67 2433-2441.

Gualillo O, Eiras S, White DW, Dieguez C \& Casanueva FF 2002 Leptin promotes the tyrosine phosphorylation of SHC proteins and SHC association with GRB2. Molecular and Cellular Endocrinology 190 83-89.

Harsch IA, Koebnick C, Wallaschofski H, Schahin SP, Hahn EG, Ficker JH, Lohmann T \& Konturek PC 2004 Resistin levels in patients with obstructive sleep apnoea syndrome - the link to subclinical inflammation? Medical Science Monitor 10 CR510-CR515.

Heilbronn LK \& Campbell LV 2008 Adipose tissue macrophages, low grade inflammation and insulin resistance in human obesity. Current Pharmaceutical Design 14 1225-1230.

Hotamisligil GS, Shargill NS \& Spiegelman BM 1993 Adipose expression of tumor necrosis factor-alpha: direct role in obesitylinked insulin resistance. Science 259 87-91.

Howard JK, Lord GM, Matarese G, Vendetti S, Ghatei MA, Ritter MA, Lechler RI \& Bloom SR 1999 Leptin protects mice from starvationinduced lymphoid atrophy and increases thymic cellularity in ob/ob mice. Journal of Clinical Investigation 104 1051-1059.

Iliopoulos D, Malizos KN \& Tsezou A 2007 Epigenetic regulation of leptin affects MMP-13 expression in osteoarthritic chondrocytes: possible molecular target for osteoarthritis therapeutic intervention. Annals of the Rheumatic Diseases 66 1616-1621.

Jia SH, Li Y, Parodo J, Kapus A, Fan L, Rotstein OD \& Marshall JC 2004 Pre-B cell colony-enhancing factor inhibits neutrophil apoptosis in experimental inflammation and clinical sepsis. Journal of Clinical Investigation 113 1318-1327.

Juge-Aubry CE \& Meier CA 2002 Immunomodulatory actions of leptin. Molecular and Cellular Endocrinology 194 1-7.

Juge-Aubry CE, Henrichot E \& Meier CA 2005 Adipose tissue: a regulator of inflammation. Best Practice and Research. Clinical Endocrinology and Metabolism 19 547-566.

Kadowaki T \& Yamauchi T 2005 Adiponectin and adiponectin receptors. Endocrine Reviews 26 439-451.

Kimura M, Tanaka S, Isoda F, Sekigawa K, Yamakawa T \& Sekihara H $1998 \mathrm{~T}$ lymphopenia in obese diabetic $(\mathrm{db} / \mathrm{db})$ mice is nonselective and thymus independent. Life Sciences 62 1243-1250.

Lago R, Gomez R, Otero M, Lago F, Gallego R, Dieguez C, GomezReino JJ \& Gualillo O 2008 A new player in cartilage homeostasis: adiponectin induces nitric oxide synthase type II and proinflammatory cytokines in chondrocytes. Osteoarthritis and Cartilage 16 1101-1109.

Lajeunesse D, Pelletier JP \& Martel-Pelletier J 2005 Osteoarthritis: a metabolic disease induced by local abnormal leptin activity? Current Rheumatology Reports 7 79-81.

Lee SW, Kim JH, Park MC, Park YB \& Lee SK 2008 Adiponectin mitigates the severity of arthritis in mice with collagen-induced arthritis. Scandinavian Journal of Rheumatology 37 260-268.
Lehrke M, Reilly MP, Millington SC, Iqbal N, Rader DJ \& Lazar MA 2004 An inflammatory cascade leading to hyperresistinemia in humans. PLoS Medicine 1 e45.

Lewicki M, Kotyla P \& Kucharz E 2008 Etanercept increases adiponectin level in woman with rheumatoid arthritis. Clinical Rheumatology 27 1337-1338.

Maeda N, Takahashi M, Funahashi T, Kihara S, Nishizawa H, Kishida K, Nagaretani H, Matsuda M, Komuro R, Ouchi N et al. 2001 PPARgamma ligands increase expression and plasma concentrations of adiponectin, an adipose-derived protein. Diabetes 50 2094-2099.

Matarese G, Leiter EH \& La Cava A 2007 Leptin in autoimmunity: many questions, some answers. Tissue Antigens 70 87-95.

Matsuzawa Y 2006 Therapy insight: adipocytokines in metabolic syndrome and related cardiovascular disease. Nature Clinical Practice. Cardiovascular Medicine 3 35-42.

Moschen AR, Kaser A, Enrich B, Mosheimer B, Theurl M, Niederegger H \& Tilg H 2007 Visfatin, an adipocytokine with proinflammatory and immunomodulating properties. Journal of Immunology 178 $1748-1758$.

Nagashima T, Okubo-Fornbacher H, Aoki Y, Kamata Y, Kimura H, Kamimura T, Nara H, Iwamoto M, Yoshio T, Okazaki H et al. 2008 Increase in plasma levels of adiponectin after administration of antitumor necrosis factor agents in patients with rheumatoid arthritis. Journal of Rheumatology 35 936-938.

Otero M, Gomez Reino JJ \& Gualillo O 2003 Synergistic induction of nitric oxide synthase type II: in vitro effect of leptin and interferongamma in human chondrocytes and ATDC5 chondrogenic cells. Arthritis and Rheumatism 48 404-409.

Otero M, Lago R, Lago F, Casanueva FF, Dieguez C, Gomez-Reino JJ \& Gualillo O $2005 a$ Leptin, from fat to inflammation: old questions and new insights. FEBS Letters $\mathbf{5 7 9}$ 295-301.

Otero M, Lago R, Lago F, Reino JJ \& Gualillo O 2005b Signalling pathway involved in nitric oxide synthase type II activation in chondrocytes: synergistic effect of leptin with interleukin-1. Arthritis Research and Therapy 7 R581-R591.

Otero M, Lago R, Gomez R, Lago F, Dieguez C, Gomez-Reino JJ \& Gualillo O 2006 Changes in plasma levels of fat-derived hormones adiponectin, leptin, resistin and visfatin in patients with rheumatoid arthritis. Annals of the Rheumatic Diseases 65 1198-1201.

Rasouli N \& Kern PA 2008 Adipocytokines and the metabolic complications of obesity. Journal of Clinical Endocrinology and Metabolism 93 S64-S73.

Reilly MP, Lehrke M, Wolfe ML, Rohatgi A, Lazar MA \& Rader DJ 2005 Resistin is an inflammatory marker of atherosclerosis in humans. Circulation 111 932-939.

Sanna V, Di Giacomo A, La Cava A, Lechler RI, Fontana S, Zappacosta S \& Matarese G 2003 Leptin surge precedes onset of autoimmune encephalomyelitis and correlates with development of pathogenic T cell responses. Journal of Clinical Investigation 111 241-250.

Sarraf P, Frederich RC, Turner EM, Ma G, Jaskowiak NT, Rivet DJ III, Flier JS, Lowell BB, Fraker DL \& Alexander HR 1997 Multiple cytokines and acute inflammation raise mouse leptin levels: potential role in inflammatory anorexia. Journal of Experimental Medicine 185 171-175.

Schaffler A, Ehling A, Neumann E, Herfarth H, Tarner I, Scholmerich J, Muller-Ladner U \& Gay S 2003 Adipocytokines in synovial fluid. JAMA 290 1709-1710.

Senolt L, Housa D, Vernerova Z, Jirasek T, Svobodova R, Veigl D, Anderlova K, Muller-Ladner U, Pavelka K \& Haluzik M 2007 Resistin in rheumatoid arthritis synovial tissue, synovial fluid and serum. Annals of the Rheumatic Diseases 66 458-463.

Simopoulou T, Malizos KN, Iliopoulos D, Stefanou N, Papatheodorou L, Ioannou M \& Tsezou A 2007 Differential expression of leptin and leptin's receptor isoform ( $\mathrm{Ob}-\mathrm{Rb})$ mRNA between advanced and minimally affected osteoarthritic cartilage; effect on cartilage metabolism. Osteoarthritis and Cartilage 15 872-883. 
Steppan CM, Bailey ST, Bhat S, Brown EJ, Banerjee RR, Wright CM, Patel HR, Ahima RS \& Lazar MA 2001 The hormone resistin links obesity to diabetes. Nature 409 307-312.

Takeda S \& Karsenty G 2008 Molecular bases of the sympathetic regulation of bone mass. Bone $\mathbf{4 2} 837-840$.

Teichtahl AJ, Wluka AE, Proietto J \& Cicuttini FM 2005 Obesity and the female sex, risk factors for knee osteoarthritis that may be attributable to systemic or local leptin biosynthesis and its cellular effects. Medical Hypotheses 65 312-315.

Tong KM, Shieh DC, Chen CP, Tzeng CY, Wang SP, Huang KC, Chiu YC, Fong YC \& Tang CH 2008 Leptin induces IL-8 expression via leptin receptor, IRS-1, PI3K, Akt cascade and promotion of NF-kap$\mathrm{paB} / \mathrm{p} 300$ binding in human synovial fibroblasts. Cellular Signalling 20 1478-1488.

Trayhurn P 2005 Endocrine and signalling role of adipose tissue: new perspectives on fat. Acta Physiologica Scandinavica 184 285-293.
Whitehead JP, Richards AA, Hickman IJ, Macdonald GA \& Prins JB 2006 Adiponectin - a key adipokine in the metabolic syndrome. Diabetes, Obesity and Metabolism 8 264-280.

Yamauchi T, Nio Y, Maki T, Kobayashi M, Takazawa T, Iwabu M, Okada-Iwabu M, Kawamoto S, Kubota N, Kubota T et al. 2007 Targeted disruption of AdipoR1 and AdipoR2 causes abrogation of adiponectin binding and metabolic actions. Nature Medicine 13 332-339.

Zhang Y, Proenca R, Maffei M, Barone M, Leopold L \& Friedman JM 1994 Positional cloning of the mouse obese gene and its human homologue. Nature 372 425-432.

Received in final form 2 February 2009

Accepted 23 February 2009

Made available online as an Accepted Preprint 24 February 2009 